This is an author produced version of a paper published in Public Health. This paper has been peer-reviewed but does not include the final publisher proofcorrections or journal pagination.

Citation for the published paper:

Carlsson, $\mathrm{F}$ and Karlson, B and Orbæk, P and Osterberg, $\mathrm{K}$ and Ostergren, P-O "Prevalence of annoyance attributed to electrical equipment and smells in a Swedish population, and relationship with subjective health and daily functioning".

Public Health. 2005 Jul;119(7):568-77. http://dx.doi.org/10.1016/j.puhe.2004.07.011

Access to the published version may require journal subscription. Published with permission from: Elsevier 


\section{Prevalence of annoyance attributed to electrical equipment and smells in a Swedish population, and relation to subjective health and daily functioning.}

Running head: Annoyance from electricity and smells, -prevalence and subjective health

Frida Carlsson $\mathrm{MSc}^{1}$, Björn Karlson $\mathrm{PhD}^{1}$, Palle Ørbæk $\mathrm{MD}^{1,2}$, Kai Österberg $\mathrm{PhD}^{1}$, Per-Olof Östergren $\mathrm{MD}^{3}$

${ }^{1}$ Department of Occupational and Environmental Medicine, Lund University Hospital, Lund University, Lund, Sweden

${ }^{2}$ National Institute of Occupational Health, Copenhagen, Denmark

${ }^{3}$ Department of Community Medicine, Malmö University Hospital, Lund University, Malmö, Sweden

The project was financially supported by the Swedish Council for Working Life and Social Research, project \#2001-0321 and 0322

Word count: 3677

\section{Corresponding Author:}

Frida Carlsson

Department of Occupational and Environmental Medicine

Barngatan 2

Lund University Hospital

22185 Lund

SWEDEN

e-mail: frida.carlsson@ymed.lu.se

Telephone: Int. +4646177437

Fax: Int. +46 46177285 


\section{Abstract}

Self-reported annoyance from electrical equipment has been in evidence since the mideighties, and the first reports of illness from everyday chemicals arose already in the 1960's. However, the extent of the problem has not yet been fully established.

\section{Aims}

The aim of this study was to estimate the prevalence of annoyance related to electrical and chemical factors in a Swedish general population, and to assess possible relations to subjective health and daily functioning.

Methods

13604 persons, representative of the population of Scania, Sweden, answered to a survey containing five questions regarding annoyance from five environmental factors; fluorescent tube lighting (FTL), visual display units (VDU), other electrical equipment, air that smells of chemicals, and other smells. The survey also obtained data on self-reported health (SRH-7), mental well-being, (GHQ-12), work situation and daily functioning.

Results

Almost one third of the respondents stated to be annoyed by at least one environmental factor. Annoyance was more frequent among women, subjects of working age and immigrants. Subjects who reported environmental annoyance scored higher on GHQ-12 and lower on SRH-7, indicating impaired subjective physical and mental well-being. They also more often reported deteriorated daily functioning.

\section{Conclusions}

Annoyance related to electrical and/or chemical factors was common in a Swedish population. Subjects reporting environmental annoyance related rated their overall health significantly poorer than the general population. The association with subjective health and functional capacity increased with severity of annoyance, which suggests that there is some connection between environmental annoyance, well-being and functional capacity. 
Key words: environmental intolerance, environmental illness, epidemiology 


\section{Introduction}

Already in the late 1950's and 60's, Theron Randolph wrote about illness arising from nonallergic susceptibility and maladaptation to environmental irritants such as environmental and indoor chemicals (1). Self-reported annoyance from electromagnetic fields (EMF) was first described in the literature in the mid eighties $(2,3)$. Most of the early reports on EMF-related complaints were mainly concerned with dermatologic symptoms associated with work with visual display units (VDU). Later on, reports of more general neurasthenic symptoms, associated not only with VDUs but with a variety of electrical equipment, were made public (4). The most frequently reported symptoms in groups suffering from sensitivity to electricity or visual display units including television and fluorescent lighting were skin complaints, fatigue, pain and dizziness (5). Those who claimed to be sensitive to electricity in general reported a wider range of symptoms than the group who was mainly sensitive to VDU or fluorescent lighting. Symptoms most frequently reported in multiple chemical sensitivity (MCS), also known as Idiopathic Environmental Intolerance, involves the central nervous system, respiratory system, and gastrointestinal tract (6).

Even though self-reported problems associated with VDUs, fluorescent lightning and other electrical devices have been recognised for almost 20 years, the extent of the problem in the general population has not been established. The presumed number of cases of "electromagnetic hypersensitivity" in European countries varied from 10 to more than 10000 (7). Concern about the problem has varied between countries, and also the types of complaints reported. In the attempts to estimate the prevalence in different European countries, Sweden and Germany seemed to have the highest number of affected persons (7). A prevalence of self-reported hypersensitivity to electrical or magnetic fields of $1.5 \%$ was reported in a city population in Stockholm, Sweden (8) and 3.2\% in a Californian population (9). In the California study, sensitivity or allergy to everyday chemicals was reported by $23.1 \%$. A combination of sensitivity to electrical devices and everyday chemicals was reported by $1.8 \%$. 
A few years previously, the same question about sensitivity to chemicals in California resulted in a prevalence of $15.9 \%$ for self-reported sensitivity (10).

Self-reported sensitivity to electricity has been found to be more common among women (8) and among those with a lower socio-economic status $(8,11)$. The Swedish study found a higher prevalence in persons born outside the Nordic countries, while the Californian study found ethnicity other than White, Black, or Hispanic to be predictive of the report of being hypersensitive to electromagnetic fields. While Hillert et al. (8) found the highest prevalence of self-reported hypersensitivity to EMF in persons aged 60-69, Frick et al. (12) found no difference between age groups in reporting "EMF-related symptoms". Women have also been found to be more susceptible to, or over-represented in complaints of, chemical sensitivity $(10,13-17)$ while the impact of factors such as ethnicity, income, and age has been less clear. A number of provocation tests have failed to show that persons experiencing sensitivity to electromagnetic fields or electrical devices were better than control persons in distinguishing real exposure to electromagnetic fields from sham-exposure $(11,18-21)$.

Subjects suffering from environmental illness mainly related to chemicals, have in previous studies been found to be more anxious, stressed, depressed, functionally disabled, reporting more medical disability, impaired functioning and more days in bed due to disability $(13,22-$ 25). In a review article, Black (26) confirmed the image of subjects with Idiopathic Environmental Intolerance (IEI) as being more depressed and scoring higher on scales of anxiety, depression and somatization. Women with self-reported poor health attributed to chemicals have been reported to show poorer overall health and increased disability (27). A qualitative study on 12 women with environmental sensitivity indicated a multiple-system involvement with changes to personal health, environment and occupation that contributed to a decline in occupational performance (28). 
Since several studies have failed to find objective signs of allergic reactions present in subjects claiming sensitivity to electricity, the only way to examine prevalences of this "syndrome" is through self-reports. Previous studies on this field have examined prevalences of self-reported sensitivity or hypersensitivity against environmental factors. However, for a person to regard him/herself as hypersensitive against some factor, there should be an annoyance reaction, or experiences of unpleasant symptoms, combined with an attribution of this annoyance or symptoms to some stimuli. The prevalence of attribution of irritation or annoyance to electricity or smell-related environmental stimuli in the general population, without necessarily leading to the subject yet regarding him/herself as hypersensitive, has not yet been examined.

Aims

The aim of this study was to estimate the prevalence of attribution of annoyance to electrical devices, chemicals and smells in a Swedish general population, and to assess the distribution of this annoyance attribution in various demographic and socioeconomic groups. We further aimed to investigate whether subjects reporting such annoyance presented reduced subjective health status and functional capacity. 


\section{Material and methods}

$\underline{\text { Subjects }}$

A postal questionnaire was sent to a non-proportional geographically stratified sample of 24 922 persons born 1919-1981 and living in Scania (Skåne, the southernmost county of Sweden) in November 1999- April 2000. 7402 women and 6202 men responded, giving a response rate of $59 \%$ of the net selection (29).

\section{The postal survey}

\section{Questions about environmental annoyance}

Five questions regarding annoyance from environmental factors were included in the survey. These questions read: "Did you during the past 14 days experience annoyance that you associate with (1) fluorescent tube lighting (FTL) / (2) visual display units (VDU) / (3) other electrical equipment / (4) breathing air that smells of chemicals / (5) other smells and if so, how much annoyance did that cause you?" with possible responses "No", "Yes, some" or "Yes, very much".

\section{Additional questions}

The survey also included questions on occupation, employment, age, country of birth, workand functional capacity, days of sick-leave. Moreover, the survey obtained data on selfreported health, SRH-7 (30) and mental well-being (General Health Questionnaire [GHQ12]; (31)). Work load in terms of demands and control was measured through the Job Content Questionnaire [JCQ] (32).

\section{Validation of questions on environmental annoyance}

As a validation of the questions on environmental annoyance, a subset of subjects $(n=84)$ that had reported "much" annoyance in the cohort study responded to a modified version of the Questionnaire on Chemical and General Environmental Sensitivity (33) approximately three years later. This questionnaire comprises questions about reactions to various environmental, physical and psychological stimuli, and showed clearly higher scores on most of the subscales in the environmentally annoyed groups compared to referents, even though, as expected in a 
sub-clinical population based group, only a minority of the annoyed subjects was classified as having MCS or electrical sensitivity (for a more detailed description, see Österberg et. al $((34)))$.

Data management

Four parallel classification models were tested independently in order to separately analyse each dimension, or combination of dimensions, of annoyance triggers:

1. VDU/FTL classification (visual display units and/or fluorescent tube lighting), defined by reporting annoyance on at least one of the questions 1 and 2.

2. NLE classification (non-lightening electrical equipment, i. e. "other electrical equipment"), defined as reporting annoyance on question 3.

3. ODOUR classification (chemicals or other smells), defined as reporting annoyance on either or both of the questions 4 and 5 .

4. BOTH classification (reporting annoyance from both some kind of electrical equipment and chemicals or smells), defined as reporting annoyance on at least one of the questions 1-3 as well as on at least one of the questions 4 and 5.

For the classification models involving two questions (i. e. models 1 and 3 ) the classification was based on the highest rating given on any of the questions. For the classification model covering five questions (BOTH, i. e. model 4) a classification of "much annoyance" required that a "much annoyance" rating had been given on at least one of the questions concerning either electrical equipment (questions 1-3) or smells (questions 4 and 5) in combination with a rating of "some annoyance" or "much annoyance" on at least one of the questions in the other category. A BOTH classification of "some annoyance" required that this rating had been given on at least one question within each of the latter categories, i.e. electrical equipment (questions 1-3) or smells (questions 4 and 5). The number of subjects in each category is presented in table 1. 


\section{$\underline{\text { Data analysis }}$}

For statistical analysis, the SPSS computer software version 11.0 was used. Odds ratios (OR) and $95 \%$ confidence intervals were estimated by use of conditional logistic regression. Confidence intervals of prevalence were computed with Confidence Interval Analysis (CIA) version 2.0 (35).

OR for SES-groups to report VDU/FTL and NLE annoyance, as well as BOTH, were calculated in relation to blue-collar workers. For ODOUR annoyance, OR for SES-groups were, in contrast, the reference level was upper white collars, since annoyance from chemicals is likely to be more common among blue-collar workers who can be assumed to be more frequently exposed to chemicals and smells. Age, gender, socio-economic status and country of birth (Sweden or other) were tested and included as confounders in the model if they, when individually introduced, changed any of the result estimates with $\geq 15 \%$ (or more than one estimate in the tables with $>20$ result estimates).

\section{$\underline{\text { Ethics }}$}

The Ethical Committee at the Medical Faculty of Lund University approved the study (LU 179-99). All the participants received written information about the survey and its purpose to increase knowledge about the health-situation in Scania, and attitudes to the health-care provided. Participants also received written information on future linkage to health care registers. 


\section{Results}

Of the respondents, $30.2 \%$ (CI 29.4-31.0) stated to be annoyed to any degree by at least one environmental factor. When starting to look at the five basic questions, "other smells" was the factor most frequently reported as annoying (table 1). Of the electrical environmental factors, VDU was the factor most frequently associated with reports of some annoyance, while fluorescent tube lightning was the factor most commonly associated with reports of much annoyance. "Other electrical equipment" was the factor, of all the five, most rarely associated with annoyance.

$27.7 \%$ (CI 27.0-28.5) of the respondents reported having experienced some annoyance from at least one environmental factor, but in most cases not by more than one factor (table 2). The proportion of subjects reporting to have experienced much annoyance by some environmental factor or factors was 5.7\% (CI 5.3-6.1). Even here, the annoyance was mostly associated with one factor only.

Women more frequently reported annoyance from environmental factors than men. Adjusted for age and SES, OR for women to report annoyance was significantly $(p<0.001)$ higher for VDU/FTL (some: 1.3 (1.2-1.5), much 1.8 (1.4-2.4)) ODOUR (some: 1.2 (1.1-1.3), much: 1.9 (1.6-2.2)) and BOTH (some: 1.4 (1.2-1.7), much:1.7 (1.3-2.1)) but not for NLE.

Subjects of working age, compared to those 65 years or older, more frequently reported environmentally attributed annoyance both regarding some and much annoyance (table 3). Immigrants had increased ORs to report annoyance from environmental factors, from 1.4 (1.2-1.7) for some ODOUR to $3.0(1.4-6.3)$ for much NLE.

All white collar workers showed an increased OR to report some VDU/FTL associated annoyance (table 4). Lower white collar workers had in addition an increased OR to report some annoyance from NLE and BOTH, as well as much annoyance from VDU/FTL and ODOUR. Increased OR for attributing annoyance to most of the examined factors, including 
BOTH was found in unemployed, disability pensioners, and students, i. e. the groups in working ages, but standing outside the labour market.

Subjects who reported annoyance attributed to electrical devices and smells scored significantly higher on the General Health Questionnaire (GHQ-12) and lower on Self-Rated Health (SRH-7), indicating lower subjective physical and mental well-being than environmentally non-annoyed subjects (table 5). Attribution of annoyance to environmental factors (i. e. electrical devices or smells) was also associated with experience of higher occupational demands and slightly lower decision latitude compared to non-annoyed subjects, resulting in a higher demand/control quotient for environmentally annoyed subjects (table 5). Furthermore, these subjects stated being stressed in every day life significantly more often than the general population (table 6). They also more frequently reported that they had quit or changed work or assignments due to sickness, injury or annoyance, but OR to have been on sick leave $>30$ days last year was increased only for those reporting much annoyance, except for the NLE group, who did not at all have increased OR for long sick leave (table 6). The environmentally annoyed groups had increased OR to report difficulties in performing everyday duties. ORs tended to be highest for subjects who reported much annoyance (table 7). Of all who reported having had difficulties in performing everyday duties, those feeling environmentally annoyed to a higher degree believed this to be due to an abiding functional reduction, compared to those who did not report annoyance attributed to environmental factors. 


\section{Discussion}

Annoyance attributed to electrical and/or chemical factors was common in the general Swedish population. To have been "very annoyed" in association to any of these factors was also common. The questions in this survey differ from previous prevalence studies (e. g. (8$10,14)$ ) in that we did not ask about suffering from sensitivity to electricity or multiple chemical sensitivity (MCS), but only about annoyance attributed to various factors, which seems to have given a larger proportion of positive answers. We do not know how many of the subjects in our study regard themselves to be "sensitive" or "hypersensitive", but the prevalence of subjects reporting annoyance from "other electrical equipment" (NLE) is similar to the prevalence of electrical hypersensitivity found in previous studies $(8,9)$. It should be noted that a segment of the population feeling discomfort related to VDU-work, may associate the question with other aspects of VDU work than electromagnetic fields. However, reporting annoyance related to environmental factors is associated with a lower level of self-reported wellbeing than the general population, and attributing irritation or annoyance to external environmental factors may have consequences, limiting the every-day life and work for the subject, even though not yet regard him/herself as "hypersensitive". Part of our findings in present study might be explained by negative affectivity in some subjects reporting annoyance from environmental factors. Negative affectivity is conceived as the propensity to experience aversive emotions, for example, anxiety, worry, depression, tension, stress and low self-esteem (36). However, even though some subjects may have such a tendency of "negative" reports, which may influence the reported degree of both annoyance and well-being, our focus of interest was on the attribution of annoyance to environmental factors. This attribution should not necessarily be affected of negative affectivity. Irrespective of negative affectivity, attributing symptoms or annoyance to external, environmental factors may lead to irrational behaviour modification, leading the subjects to restrict their life with the intention to avoid environmental stimuli, which may be present in both their occupational- 
and home environment. Although being recommended by some as a treatment option for MCS $(37,38)$, avoidance behaviour in subjective hypersensitivity could presumably rather increase than decrease the problems. The recommendation to strive for a "clean" environment through avoidance behaviour has been criticized. Instead, it is suggested that systematic avoidance of noxious odors preserves a high sensitivity to them and prevents adaptation of as well the current odor as similar ones (39). Avoidance actions may also be associated with high costs for both the individual and the workplace, when trying to decontaminate the environment from the environmental stimuli (39).

As in previous studies, we found a higher prevalence among women. This may in part be explained by the fact that women generally score higher and more widespread complaints on self-report scales than men (40). Immigrants more frequently reported annoyance from electrical and chemical factors, which was also found in another Swedish prevalence study (8). It may reflect a true difference between immigrants and native Swedes, but may also depend on a divergent interpretation of the response scales.

Persons with lower socio-economic status reported more annoyance from environmental factors, and groups in working ages, but outside the labour market more frequently reported "much" annoyance. Being a cross-sectional study, the causality in this relation cannot be determined. It may reflect that persons with much annoyance have difficulties to obtain and maintain gainful work, but being outside the labour market may as well lead to worse health, which by some might be attributed to various environmental factors.

Blue-collar workers seemed to be more annoyed by chemicals/odours, while white-collar workers more frequently attributed annoyance to electrical factors like VDU or fluorescent lighting which is concordant with the presumed exposure in their work. This can be interpreted as either that the equipment causes annoyance in itself, or as a tendency to attribute general annoyance to present surroundings. 
Persons of working age tend to report more annoyance than those aged 65 and over. This may indicate a true age-difference, but may also be explained by the difference in life- and stresssituation between persons in active employment versus senior citizens.

Subjects reporting annoyance related to electrical devices, chemicals and smells rated their overall health as significantly poorer than the general population and they had higher GHQscore, indicating lower mental well-being. It is difficult to estimate the clinical significance of the reduction in subjective well-being, as the differences were not very great but due to the large groups they were highly statistically significant. Still, the mean GHQ-values were for most annoyed groups great enough to indicate a substantial mental load. The results also indicate a reduced functional capacity, more frequent stress in daily life and an increased demand/control quotient, indicating higher work load among the environmentally-annoyed subjects. The reduction in subjective health and functional capacity increased with severity of environmentally associated annoyance reports. These relations may be moderated by negative affectivity, as discussed above, but may as well reflect a true relationship between environmentally attributed annoyance, and reduced subjective health and daily functioning. However, being a cross-sectional study, possible temporal or causal relationships cannot be determined. There is also a possibility that these subjects in fact suffer from other diseases, leading to the decreased health status. Regarding health care consumption, this seems, however, not to be the case (Carlsson et al., unpublished data).

The NLE group reported the lowest subjective health status and functional capacity, which is consistent with previous studies in which subjects suffering from "hypersensitivity" to a wide range of electrical devices were less able to work, and had a poorer prognosis than subjects with symptoms related mainly to VDU/FTL (41). In this study, the NLE annoyed subjects did not show an increased rate of long-term sick leave, despite impaired health. Although they had the most affected subjective health status, reported to have been prevented from performing every-day duties, and to have changed work due to sickness, injury or annoyance, 
they seemed not to have been on sick-leave to a higher degree than the rest of the population. Those who were "much" annoyed by NLE, however, tended to have increased odds ratios for sick leave, although not reaching statistical significance. This lack of significance might depend on smaller group sizes, causing a wider confidence interval.

\section{$\underline{\text { Methodological considerations }}$}

Selection bias

The proportion of non-participants was substantial (59\% response rate). Even though that is a quite normal response rate, it gave rise to the question as to how representative the final population was. There is a general tendency towards slightly healthier participants than nonparticipants in surveys. If there is a special focus of the survey, it may entice persons with a special interest in that topic. In this case, the focus of the survey was not environmental annoyance, but attitudes to the health care provided by the region. So, the risk of an overrepresentativity of environmentally-annoyed subjects should not be a problem. Subjects who had had no experience of health care for a long time, might have felt that they had nothing to contribute, and hence desisted from responding to the survey which would decrease the overrepresentativity of healthy responders.

An analysis of representativity was performed, comparing the cohort with the total population in Scania. More women than men, and a larger proportion of the older age groups, responded to the survey. The differences, however, are not extreme in any way. Calculations on weighted (for age, gender and geographic area) data, that levels out the differences in proportion of males/females and age groups, gave similar results to the use of unweighted data. The respondents also had about the same health-care consumption as the Scanian population in total, indicating a representative health status of the respondents, thus being neither healthier nor unhealthier than the total population in Scania (Carlsson et al., unpublished data). 


\section{Misclassification}

As in any survey, the responders' subjective interpretation of the questions forms the answers. The questions about annoyance attributed to environmental factors might be interpreted in slightly various ways depending on the reader, e. g. some of those who stated to have been annoyed by "other smells" may in fact aim to a highly temporary experience which should not be interpreted as a general sensitivity to smells. However, as described in the methods section, the responses to the five basic questions converged with the response to an elaborated questionnaire on general environmental sensitivity (33), indicating that the basic questions in a valid way reflect crucial aspects of environmental intolerance (34).

\section{Confounding}

Asthma is associated with sensitivity to certain smelling irritants, such as cigarette smoke. The prevalence of traditional allergies/asthma in this population was not known, hence we do not know if there are a larger proportion of asthma sufferers among the subjects who stated to be annoyed by chemicals and smells.

\section{Conclusion}

In conclusion, annoyance attributed to environmental factors was common in a general Swedish population. Such annoyance attribution was most frequent among women, persons outside the labour market, immigrants, and persons in occupationally active ages. Subjects associating annoyance with electrical devices, chemicals and smells rated their overall health and functional capacity significantly poorer than the general population.

\section{Acknowledgements}

I want to express my gratitude to Juan Merlo, for valuable discussions and comments on the methods. This study was financially supported by the Swedish Council for Working Life and Social Research, project \#2001-0321 and 0322. 


\section{References}

1. Randolph TG. Ecologic Orientation in Medicine: Comprehensive Environmental Control in Diagnosis and Therapy. Ann Allergy 1965;23:7-22.

2. Knave BG, Wibom RI, Voss M, Hedstrom LD, Bergqvist UO. Work with video display terminals among office employees. I. Subjective symptoms and discomfort. Scand J Work Environ Health 1985;11(6):457-66.

3. Knave BG, Wibom RI, Bergqvist UO, Carlsson LL, Levin MI, Nylen PR. Work with video display terminals among office employees. II. Physical exposure factors. Scand J Work Environ Health 1985;11(6):467-74.

4. Bergqvist U, Brante T, Fransson K, Mild K, Hillert L, Johansson O, et al. Elektromagnetiska fält, elöverkänslighet och neurologisk sjukdom -en kunskapsöversikt (Electromagnetic fields, electromagnetic hypersensitivity and neurological disease -a review. In Swedish). Solna, Sweden: National Institute for Working Life; 1998.

5. Bergdahl J. Psychologic aspects of patients with symptoms presumed to be caused by electricity or visual display units. Acta Odontol Scand 1995;53(5):304-10.

6. Sparks PJ. Idiopathic environmental intolerances: overview. Occup Med 2000;15(3):497-510.

7. Bergqvist U, Vogel E, eds. Possible Health Implications of Subjective Symptoms and Electromagnetic Fields. A report prepared by a European group of experts for the European Commission. Solna, Sweden: European Commission DG V, National Institute for Working Life; 1997.

8. Hillert L, Berglind N, Arnetz BB, Bellander T. Prevalence of self-reported hypersensitivity to electric or magnetic fields in a population-based questionnaire survey. Scand J Work Environ Health 2002;28(1):33-41. 
9. Levallois P, Neutra R, Lee G, Hristova L. Study of self-reported hypersensitivity to electromagnetic fields in California. Environ Health Perspect 2002;110 Suppl 4:619-23. 10. Kreutzer R, Neutra RR, Lashuay N. Prevalence of people reporting sensitivities to chemicals in a population-based survey. Am J Epidemiol 1999;150(1):1-12.

11. Levallois P. Hypersensitivity of human subjects to environmental electric and magnetic field exposure: a review of the literature. Environ Health Perspect 2002;110 Suppl 4:613-8.

12. Frick U, Rehm J, Eichhammer P. Risk perception, somatization, and self report of complaints related to electromagnetic fields--a randomized survey study. Int J Hyg Environ Health 2002;205(5):353-60.

13. Bell IR, Miller CS, Schwartz GE, Peterson JM, Amend D. Neuropsychiatric and somatic characteristics of young adults with and without self-reported chemical odor intolerance and chemical sensitivity. Arch Environ Health 1996;51(1):9-21.

14. Bell IR, Schwartz GE, Peterson JM, Amend D. Self-reported illness from chemical odors in young adults without clinical syndromes or occupational exposures. Arch Environ Health 1993;48(1):6-13.

15. Bolt HM, Kiesswetter E. Is multiple chemical sensitivity a clinically defined entity? Toxicol Lett 2002;128(1-3):99-106.

16. Kipen HM, Hallman W, Kelly-McNeil K, Fiedler N. Measuring chemical sensitivity prevalence: a questionnaire for population studies. Am J Public Health 1995;85(4):574-7.

17. Meggs WJ, Dunn KA, Bloch RM, Goodman PE, Davidoff AL. Prevalence and nature of allergy and chemical sensitivity in a general population. Arch Environ Health 1996;51(4):275-82.

18. Flodin U, Seneby A, Tegenfeldt C. Provocation of electric hypersensitivity under everyday conditions. Scand J Work Environ Health 2000;26(2):93-8.

19. Hietanen M, Hamalainen AM, Husman T. Hypersensitivity symptoms associated with exposure to cellular telephones: no causal link. Bioelectromagnetics 2002;23(4):264-70. 
20. Lonne-Rahm S, Andersson B, Melin L, Schultzberg M, Arnetz B, Berg M. Provocation with stress and electricity of patients with "sensitivity to electricity". J Occup Environ Med 2000;42(5):512-6.

21. Lyskov E, Sandstrom M, Mild KH. Provocation study of persons with perceived electrical hypersensitivity and controls using magnetic field exposure and recording of electrophysiological characteristics. Bioelectromagnetics 2001;22(7):457-62.

22. Bergdahl J, Bergdahl M. Environmental illness: evaluation of salivary flow, symptoms, diseases, medications, and psychological factors. Acta Odontol Scand 2001;59(2):104-10.

23. Black DW, Doebbeling BN, Voelker MD, Clarke WR, Woolson RF, Barrett DH, et al. Quality of life and health-services utilization in a population-based sample of military personnel reporting multiple chemical sensitivities. J Occup Environ Med 1999;41(10):92833.

24. Magnavita N. Cacosmia in healthy workers. Br J Med Psychol 2001;74(Pt 1):121-7. 25. Sparks PJ, Daniell W, Black DW, Kipen HM, Altman LC, Simon GE, et al. Multiple chemical sensitivity syndrome: a clinical perspective. I. Case definition, theories of pathogenesis, and research needs. J Occup Med 1994;36(7):718-30.

26. Black DW. The relationship of mental disorders and idiopathic environmental intolerance. Occup Med 2000;15(3):557-70.

27. Bell IR, Peterson JM, Schwartz GE. Medical histories and psychological profiles of middle-aged women with and without self-reported illness from environmental chemicals. J Clin Psychiatry 1995;56(4):151-60.

28. Peachey-Hill C, Law M. Impact of environmental sensitivity on occupational performance. Can J Occup Ther 2000;67(5):304-13.

29. Östergren P-O, Merlo J, Lindström M, Rosvall M, Kahn FA, Lithman T. Hälsoförhållanden i Skåne. Malmö: Folkhälsoenkät Skåne 2000 (Health conditions in Scania. 
Public Health Survey in Scania 2000): Region Skåne, Kommunförbundet Skåne och Skåne läns Allmänna Försäkringskassa; 2001.

30. Eriksson I, Unden AL, Elofsson S. Self-rated health. Comparisons between three different measures. Results from a population study. Int J Epidemiol 2001;30(2):326-33.

31. Goldberg D, Williams P. A users' guide to the General Health Questionnaire. Windsor: NFER-Nelson; 1988.

32. Karasek R, Brisson C, Kawakami N, Houtman I, Bongers P, Amick B. The Job Content Questionnaire (JCQ): an instrument for internationally comparative assessments of psychosocial job characteristics. J Occup Health Psychol 1998;3(4):322-55.

33. Kiesswetter E, Sietmann B, Zupanic M, van Thriel C, Golka K, Seeber A. Neurobehavioral aspects of the prevalence and etiology of "multiple chemical sensitivity"(Verhaltenstoxikologische Aspekte der Prävalenz und Ätiologie "multipler chemischer Sensitivität"). In German. Allergologie 1999;22:719-35.

34. Österberg K, Persson R, Karlson B, Ørbæk P. Annoyance and performance of three environmentally intolerant groups during experimental challenge with chemical odors. Scand J Work Environ Health 2004;30(6):486-96.

35. Altman DG, Machin D, Bryant TN, Gardner MJ, eds. Statistics with confidence. 2nd ed. Bristol: BMJ Book; 2000.

36. Watson D, Pennebaker JW. Health complaints, stress, and distress: exploring the central role of negative affectivity. Psychol Rev 1989;96(2):234-54.

37. Ross GH. Treatment options in multiple chemical sensitivity. Toxicol Ind Health 1992;8(4):87-94.

38. Ziem GE. Multiple chemical sensitivity: treatment and followup with avoidance and control of chemical exposures. Toxicol Ind Health 1992;8(4):73-86.

39. Guglielmi RS, Cox DJ, Spyker DA. Behavioral treatment of phobic avoidance in multiple chemical sensitivity. J Behav Ther Exp Psychiatry 1994;25(3):197-209. 
40. Van Wijk CMTG, Kolk AM. Sex differences in physical symptoms: The contribution of symptom perception theory. Soc. Sci. Med. 1997;45(2):231-246.

41. Stenberg B, Bergdahl J, Edvardsson B, Eriksson N, Linden G, Widman L. Medical and social prognosis for patients with perceived hypersensitivity to electricity and skin symptoms related to the use of visual display terminals. Scand J Work Environ Health 2002;28(5):34957. 
Table 1. Prevalence of annoyance related to different environmental factors ( $\mathrm{N}=13$ 381)

\begin{tabular}{lcccc}
\hline & \multicolumn{2}{l}{ Some annoyance } & \multicolumn{2}{l}{ Much annoyance } \\
& $\mathrm{N}$ & $\%(95 \% \mathrm{CI})$ & $\mathrm{N}$ & $\%(95 \% \mathrm{CI})$ \\
\cline { 2 - 5 } Visual Display Unit VDU & 1294 & $9.7(9.2-10.2)$ & 107 & $0.8(0.6-1.0)$ \\
Fluorescent tube lighting FTL & 1045 & $7.8(7.4-8.3)$ & 183 & $1.4(1.2-1.6)$ \\
Other electrical equipment NLE & 367 & $2.7(2.5-3.0)$ & 50 & $0.4(0.3-0.5)$ \\
Chemicals & 1352 & $10.1(9.6-10.6)$ & 325 & $2.4(2.2-2.7)$ \\
Other smells & 1768 & $13.2(12.6-13.8)$ & 403 & $3.0(2.7-3.3)$ \\
VDU/FTL & 1812 & $13.5(13.0-14.1)$ & 253 & $1.9(1.7-2.1)$ \\
ODOUR & 2229 & $16.7(16.0-17.3)$ & 554 & $4.1(3.8-4.5)$ \\
BOTH & 589 & $4.4(4.1-4.8)$ & 315 & $2.4(2.1-2.6)$ \\
\hline ODOUR & & & &
\end{tabular}

ODOUR $=$ chemicals/other smells

$\mathrm{BOTH}=$ any electrical factor and chemicals/other smells 
Table 2. Prevalence of subjects reporting annoyance from 0-5 environmental factors.

\begin{tabular}{|c|c|c|c|c|}
\hline \multirow[t]{2}{*}{ N. of annoying factors } & \multicolumn{2}{|c|}{ Some annoyance } & \multicolumn{2}{|c|}{ Much annoyance } \\
\hline & $\mathrm{N}$ & $\%(95 \% \mathrm{CI})$ & $\mathrm{N}$ & $\%(95 \% \mathrm{CI})$ \\
\hline 0 & 9671 & $72.3(71.5-73.0)$ & 12621 & $94.3(93.9-94.7)$ \\
\hline 1 & 2190 & $16.4(15.7-17.0)$ & 511 & $3.8(3.5-4.1)$ \\
\hline 2 & 1081 & $8.1(7.6-8.5)$ & 210 & $1.6(1.4-1.8)$ \\
\hline 3 & 312 & $2.3(2.1-2.6)$ & 25 & $0.2(0.1-0.3)$ \\
\hline 4 & 97 & $0.7(0.6-0.9)$ & 8 & $0.1(0.0-0.1)$ \\
\hline 5 & 30 & $0.2(0.2-0.3)$ & 6 & $0.04(0.02-0.1)$ \\
\hline
\end{tabular}


Table 3. OR (95\% CI) for different age-groups to report annoyance from environmental factors. Compared to age-group $\geq 65$.

\begin{tabular}{|c|c|c|c|c|}
\hline \multirow[b]{2}{*}{ Age group } & \multicolumn{4}{|l|}{ Some annoyance } \\
\hline & VDU/FTL n 13128 & NLE n 13331 & ODOUR n 12827 & BOTH n 13066 \\
\hline$<35$ & $5.1(4.2-6.3)$ & $3.1(2.1-4.6)$ & $1.9(1.6-2.2)$ & $4.9(3.5-7.2)$ \\
\hline $35-44$ & $4.9(3.9-6.1)$ & $2.7(1.8-4.1)$ & $1.7(1.4-2.0)$ & $4.7(3.2-6.8)$ \\
\hline $45-54$ & $4.3(3.5-5.4)$ & $2.9(1.9-4.4)$ & $1.5(1.3-1.7)$ & $3.7(2.6-5.5)$ \\
\hline \multirow[t]{3}{*}{$55-64$} & $3.3(2.6-4.1)$ & $1.9(1.2-3.0)$ & $1.3(1.1-1.5)$ & $2.7(1.8-4.0)$ \\
\hline & \multicolumn{4}{|l|}{ Much annoyance } \\
\hline & VDU/FTL n 11569 & NLE n 13014 & ODOUR n 11152 & BOTH n 12793 \\
\hline$<35$ & $4.0(2.5-6.4)$ & $2.4(0.8-7.4)$ & $1.1(0.9-1.5)$ & $3.9(2.5-6.3)$ \\
\hline $35-44$ & $3.5(2.1-5.8)$ & $2.6(0.8-8.5)$ & $1.1(0.8-1.5)$ & $3.1(1.9-5.1)$ \\
\hline $45-54$ & $3.2(1.9-5.3)$ & $3.2(1.1-9.9)$ & $1.3(1.0-1.8)$ & $3.8(2.3-6.1)$ \\
\hline $55-64$ & $1.6(0.9-2.8)$ & $3.4(1.1-10.6)$ & $1.4(1.1-1.8)$ & $2.7(1.6-4.5)$ \\
\hline
\end{tabular}

VDU=visual display unit, FTL= fluorescent tube lighting, NLE=non-lightening electrical equipment, ODOUR=chemicals/smells, BOTH=any electrical factor and chemicals/smells 
Table 4. OR (95\% CI) for different socio-economic categories to report annoyance from environmental factors. Adjusted for age and country of birth.

\begin{tabular}{|c|c|c|c|c|}
\hline & \multicolumn{4}{|c|}{ Some annoyance } \\
\hline & $\begin{array}{l}\text { VDU/FTL } \\
\end{array}$ & NLE & ODOUR & BOTH \\
\hline & n 11705 & n 11888 & n 11450 & n 11659 \\
\hline Blue-collar worker & 1 & 1 & $1.3(1.1-1.6)$ & 1 \\
\hline Lower white-collar & $2.6(2.1-3.1)$ & $1.9(1.2-2.8)$ & $1.2(0.9-1.4)$ & $1.5(1.1-2.0)$ \\
\hline Middle white-collar & $1.8(1.5-2.1)$ & $1.2(0.8-1.8)$ & $1.1(0.9-1.3)$ & $1.2(0.9-1.6)$ \\
\hline Upper white-collar & $1.5(1.3-1.9)$ & $0.6(0.4-1.1)$ & 1 & $1.0(0.7-1.4)$ \\
\hline Self-employed/ farmer & $0.8(0.6-1.2)$ & $1.7(1.1-2.8)$ & $1.0(0.8-1.3)$ & $0.9(0.5-1.3)$ \\
\hline Disability pensioner & $0.9(0.7-1.3)$ & $2.8(1.7-4.5)$ & $1.1(0.9-1.5)$ & $0.8(0.5-1.2)$ \\
\hline Unemployed & $1.5(1.1-1.9)$ & $2.0(1.3-3.2)$ & $1.2(0.9-1.5)$ & $1.2(0.8-1.8)$ \\
\hline Student & $2.0(1.6-2.4)$ & $1.3(0.8-2.0)$ & $1.4(1.1-1.7)$ & $1.4(1.1-2.0)$ \\
\hline \multirow[t]{4}{*}{ Pensioner } & $0.4(0.3-0.5)$ & $1.0(0.6-1.7)$ & $0.9(0.7-1.1)$ & $0.4(0.2-0.6)$ \\
\hline & \multicolumn{4}{|c|}{ Much annoyance } \\
\hline & 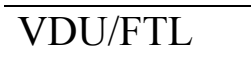 & NLE & ODOUR & BOTH \\
\hline & n 10326 & n 11614 & n 9943 & n 11402 \\
\hline Blue-collar worker & 1 & 1 & $2.0(1.2-3.1)$ & 1 \\
\hline Lower white-collar & $1.9(1.2-3.1)$ & $1.9(0.4-8.5)$ & $2.1(1.3-3.6)$ & $1.8(1.1-2.7)$ \\
\hline Middle white-collar & $1.5(0.9-2.3)$ & $2.7(0.8-9.8)$ & $1.5(0.9-2.6)$ & $1.0(0.6-1.6)$ \\
\hline Upper white-collar & $1.3(0.8-2.2)$ & $2.7(0.7-10.2)$ & 1 & $1.0(0.6-1.7)$ \\
\hline Self-employed/ farmer & $0.8(0.4-1.8)$ & $3.0(0.7-13.6)$ & $1.7(1.0-3.1)$ & $0.9(0.5-1.8)$ \\
\hline Disability pensioner & $3.0(1.7-5.5)$ & $3.7(0.9-15.1)$ & $5.3(3.2-8.6)$ & $2.6(1.5-4.3)$ \\
\hline Unemployed & $2.6(1.6-4.4)$ & $2.7(0.6-12.1)$ & $3.5(2.1-5.9)$ & $2.5(1.6-4.0)$ \\
\hline Student & $1.6(1.0-2.6)$ & $3.5(0.9-13.4)$ & $2.3(1.3-3.9)$ & $1.7(1.1-2.7)$ \\
\hline Pensioner & $1.3(0.6-2.8)$ & $1.0(0.2-5.0)$ & $2.3(1.3-3.8)$ & $0.7(0.4-1.3)$ \\
\hline
\end{tabular}

$\mathrm{VDU}=$ visual display unit, FTL = fluorescent tube lighting, NLE=non-lightening electrical equipment, $\mathrm{ODOUR}=$ chemicals/smells, $\mathrm{BOTH}=$ any electrical factor and chemicals/smells 
Table 5. Mean (95\% CI) Self-rated health (SRH), mental well-being (GHQ-12 score) and work load (demand/control quotient), among environmentally annoyed subjects.

Reported No N little

annoyance

\begin{tabular}{|c|c|c|c|c|c|}
\hline Mean & $95 \% \mathrm{CI}$ & Mean & $95 \% \mathrm{CI}$ & Mean & $95 \% \mathrm{CI}$ \\
\hline
\end{tabular}

Mental

wellbeing, GHQ-

$12(\mathrm{n}=13355)$

$\begin{array}{lllllll}\text { VDU/FTL } & 1.94 & 1.93-1.95 & 2.08 & 2.06-2.10 & 2.19 & 2.14-2.23 \\ \text { NLE } & 1.95 & 1.95-1.96 & 2.16 & 2.11-2.20 & 2.49 & 2.38-2.60 \\ \text { ODOUR } & 1.94 & 1.93-1.95 & 2.03 & 2.01-2.04 & 2.16 & 2.13-2.20 \\ \text { BOTH } & 1.95 & 1.94-1.95 & 2.10 & 2.07-2.13 & 2.28 & 2.24-2.33\end{array}$

Self-rated health,

SRH ( $n=12$ 913)

\begin{tabular}{|c|c|c|c|c|c|c|}
\hline VDU/FTL & 5.19 & $5.16-5.21$ & 4.70 & $4.64-4.76$ & 4.29 & $4.12-4.45$ \\
\hline NLE & 5.13 & $5.10-5.15$ & 4.49 & $4.35-4.62$ & 3.72 & $3.35-4.10$ \\
\hline ODOUR & 5.21 & $5.19-5.24$ & 4.79 & $4.73-4.84$ & 4.28 & $4.17-4.3$ \\
\hline BOTH & 5.16 & $5.13-5.18$ & 4.54 & $4.43-4.64$ & 4.08 & $3.94-4.2$ \\
\hline
\end{tabular}

Demand/control

BOTH

5.16

5.13-5.18

4.54

4.43-4.64

4.08

$3.94-4.23$

quotient

$(\mathrm{n}=8382)$

$\begin{array}{llllllr}\text { VDU/FTL } & 0.88 & 0.87-0.88 & 0.93 & 0.92-0.94 & 0.98 & 0.95-1.01 \\ \text { NLE } & 0.88 & 0.88-0.89 & 0.94 & 0.91-0.97 & 1.11 & 1.02-1.19 \\ \text { ODOUR } & 0.87 & 0.87-0.88 & 0.93 & 0.91-0.94 & 0.98 & 0.95-1.01 \\ \text { BOTH } & 0.88 & 0.87-0.88 & 0.94 & 0.92-0.96 & 1.02 & 0.98-1.05\end{array}$

$\mathrm{VDU}=$ visual display unit, $\mathrm{FTL}=$ fluorescent tube lighting, $\mathrm{NLE}=$ non-lightening electrical equipment, ODOUR=chemicals/smells, $\mathrm{BOTH}=$ any

electrical factor and chemicals/smells 
Table 6. Self-reported stress and work capacity in environmentally-annoyed groups. Results from logistic regression, OR (95\% CI) $\mathrm{n}$ (included in analysis).

\begin{tabular}{|c|c|c|c|c|c|c|c|}
\hline \multirow[b]{2}{*}{ "Often stressed in daily life" } & & \multicolumn{3}{|c|}{ Some annoyance } & \multicolumn{3}{|c|}{ Much annoyance } \\
\hline & & OR & $95 \% \mathrm{CI}$ & $\mathrm{n}$ & OR & $95 \% \mathrm{CI}$ & $\mathrm{n}$ \\
\hline & VDU/FTL & 1.9 & $1.7-2.2$ & 11749 & 3.0 & $2.2-3.9$ & 10371 \\
\hline & NLE & 2.5 & $2.0-3.2$ & 11930 & 5.2 & $2.7-10.0$ & 11658 \\
\hline & ODOUR & 1.7 & $1.5-1.9$ & 11494 & 2.4 & $2.0-3.0$ & 9974 \\
\hline & BOTH & 1.9 & $1.6-2.3$ & 11702 & 3.6 & $2.8-4.6$ & 11442 \\
\hline \multicolumn{8}{|c|}{$\begin{array}{l}\text { "Changed work due to sickness, injury } \\
\text { or annoyance" }\end{array}$} \\
\hline & VDU/FTL & 1.6 & $1.4-1.9$ & 10983 & 2.8 & $2.0-3.9$ & 9656 \\
\hline & NLE & 1.5 & $1.1-2.1$ & 11151 & 4.2 & $2.0-9.0$ & 10890 \\
\hline & ODOUR & 1.7 & $1.5-2.0$ & 10755 & 3.4 & $2.7-4.2$ & 9333 \\
\hline & BOTH & 1.8 & $1.4-2.3$ & 10936 & 3.0 & $2.2-4.0$ & 10682 \\
\hline \multicolumn{8}{|l|}{ Sick-absent $>30$ days last year } \\
\hline & VDU/FTL & 1.2 & $0.9-1.6$ & 3474 & 2.6 & $1.5-4.5$ & 2914 \\
\hline & NLE & 1.0 & $0.5-1.8$ & 3546 & 3.4 & $1.0-11.5$ & 3445 \\
\hline & ODOUR & 1.0 & $0.8-1.3$ & 3426 & 2.8 & $1.8-4.3$ & 2823 \\
\hline & BOTH & 1.4 & $0.9-2.1$ & 3454 & 2.5 & $1.5-4.1$ & 3353 \\
\hline
\end{tabular}

$\mathrm{VDU}=$ visual display unit, $\mathrm{FTL}=$ fluorescent tube lighting, $\mathrm{NLE}=$ non-lightening electrical equipment, ODOUR=chemicals/smells, $\mathrm{BOTH}=$ any electrical factor and chemicals/smells 
Table 7. Functional capacity in environmentally-annoyed groups. Results from logistic regression, OR (95\% CI) n (included in analysis).

\begin{tabular}{|c|c|c|c|c|c|c|c|}
\hline \multirow[b]{2}{*}{$\begin{array}{l}\text { Prevented from performing everyday } \\
\text { duties* }\end{array}$} & & \multicolumn{3}{|c|}{ Some annoyance } & \multicolumn{3}{|c|}{ Much annoyance } \\
\hline & & OR & $95 \% \mathrm{CI}$ & $\mathrm{n}$ & OR & $95 \% \mathrm{CI}$ & $\mathrm{n}$ \\
\hline & NLE & 2.0 & $1.5-2.6$ & 11260 & 7.3 & $3.7-14.3$ & 11003 \\
\hline & ODOUR & 1.5 & $1.3-1.7$ & 10849 & 2.9 & $2.3-3.5$ & 9423 \\
\hline \multicolumn{8}{|l|}{ Believe the prevention is due to an } \\
\hline \multicolumn{8}{|l|}{ abiding functional reduction** } \\
\hline & VDU/FTL & 1.6 & $1.2-2.1$ & 1642 & 4.0 & $2.1-7.5$ & 1416 \\
\hline & BOTH & 1.8 & $1.2-2.7$ & 1621 & 2.6 & $1.6-4.2$ & 1598 \\
\hline
\end{tabular}

\footnotetext{
* Adjusted for socioeconomic status ** Adjusted for age and socioeconomic status
}

$\mathrm{VDU}=$ visual display unit, $\mathrm{FTL}=$ fluorescent tube lighting, $\mathrm{NLE}=$ non-lightening electrical equipment, $\mathrm{ODOUR}=\mathrm{chemicals} / \mathrm{smells}$, $\mathrm{BOTH}=$ any electrical factor and chemicals/smells 